\title{
The Influence of Convenience on the Usage of Learning Management System
}

\author{
Lubna A. Hussein and Mohd Faiz Hilmi \\ School of Distance Education, \\ Universiti Sains Malaysia, Malaysia \\ lubnafatlawi@gmail.com \\ faiz@usm.my
}

\begin{abstract}
The advancement in internet-based learning technologies together with the national agenda towards globalized online education in Malaysia have prompted the learning management system (LMS) to become an important channel for institutions of higher education to effectively deliver education to students. Since user resistance has been known to be a stumbling block in the implementation of the LMS, it is crucial for the institutions to acknowledge that comprehensive adoption by users relies heavily on user acceptance. Moreover, since some institutions may have even made it compulsory for students to use the LMS, user acceptance of the LMS should be studied in the sense that using LMS is likable and pleasurable. Although the features of the technical capability of the LMS are important, it has been asserted that having the feeling of personal convenience when using the LMS is even more important to the users. With the amount of financial effort and manpower involved in implementing the LMS by institutions in Malaysia towards fulfilling the online learning agenda of the nation, it is important to study whether the convenience factor as an individual impact can play the partial role of influencing Malaysian students' satisfaction of the LMS which would in turn influence them to use the LMS. Based on the Information System Success Model by DeLone and McLean, this study establishes vital process factors regarding the LMS usage among university students in Malaysia. Hence, in this study, LMS usage by students is measured by the degree of students' acceptance of the LMS. An online survey has been done to collect data from 212 students of two large public universities in Malaysia. Structural equation modeling has been used to test the relationships in the conceptual model. The results of data analysis using the PLS-SEM technique employed in the study have indicated that student satisfaction is positively influenced by factors of information quality, system quality, service quality and convenience. LMS usage has been found to be positively impacted by student satisfaction while student satisfaction has been found to have significant mediation effect. The findings from this study can be utilized by institutions committed towards having successful implementation of the LMS. In enhancing LMS usage by the students, the institutions of higher education can consider focusing on the necessary steps towards increasing student satisfaction. Meanwhile, to increase student satisfaction, apart from improving the information quality, system quality and service quality, institutions should also seriously consider promoting the LMS to the students by highlighting the individual impact of the LMS in terms of convenience.
\end{abstract}

Keywords: DeLone and McLean Information System Success Model, learning management system (LMS), student satisfaction, convenience, individual impact

\section{Introduction}

The advancement of the internet has propelled the e-learning explosion where it brings about various ways for e-learning including the learning management system (LMS). LMS can be defined as a form of online system that enables organization of learning content and provides accessibility to online communication for learners and instructors (Aldiab et al., 2019). LMS has been implemented in many universities and colleges worldwide (Dorobat, Corbea and Muntean, 2019; Nawaz, 2019; Mtebe and Raphael, 2018). In South East Asia, among others, LMS has been utilized in several countries, including Singapore (Chaw and Tang, 2018), Thailand (Thongsri, Shen and Bao, 2019) and Malaysia (Dulkaman and Ali, 2016).

User satisfaction is an important topic in view of the rapid growth in the number of institutions using the LMS, where the LMS has been used popularly in the learning process. Student satisfaction is considered to be one of the central components in identifying the attributes of online learning (Soffer and Nachmias, 2018). For this purpose, universities need to continually gather information about student satisfaction (Gee, 2018), which is not only a significant determinant of programme and learner-related outcomes, but also a positive demonstrator of learners' perceived learning skills. It is important to consider student satisfaction because of its contribution to academic performance (Rahman, Uddin and Dey, 2021). Moreover, student satisfaction will remain an important contributing factor to affect LMS usage, even if the LMS is made compulsory for students to use.

Also, the availability of study materials and the ease of keeping track of on-going activities provides the feeling of convenience to the LMS use. In addition to that, the sense of convenience may also be contributed to the easy interaction and swift collaboration with the lecturers as well as among students through the LMS. 
Convenience is considered an important factor that influences the use of LMS (Mokhtar, Katan and Hidayat-urRehman, 2018).

Malaysia has formalized the national agenda towards globalized online education. A blueprint for the period of 2015-2025 towards evolving into a higher education scenario, which includes focusing on the shift towards globalized online education, has been developed by the Ministry of Higher Education of Malaysia (Ministry of Education Malaysia, 2015). To embrace this shift, the learning management system (LMS) has been prompted more than ever to be utilized by institutions in Malaysia. Therefore, it is relevant to consider LMS usage by students as the organizational impact of the institutions. Meanwhile, since the sense of convenience may serve as an impact to LMS users in terms of instilling positive emotions and enabling cognitive possibilities, convenience can be considered as individual impact.

Therefore, the objective of this paper is to determine significant factors contributing to LMS use among university students in Malaysia using the framework of the DeLone and McLean model (D\&M model) with convenience as an individual impact and LMS usage as an organizational impact. The organization of this paper is as follows. The first section lays out the background and motivation of the research. Section 2 provides the theoretical background of the D\&M model used in this study. The description of the proposed research model is given in Section 3. Sections 4 and 5 elaborate on the methods and the results of the study while Sections 6 and 7 consist of the discussion, conclusion as well as the suggestions for future studies.

\section{Theoretical Background}

In the past 30 years, several models have been postulated in a bid to understand the factors that influence an individual's use of technology. Models such as the unified theory of acceptance and use of technology (UTAUT) by (Venkatesh et al., 2003), the technology acceptance model (Davis, 1989), and the DeLone and McLean Information System Success Model (DeLone and McLean, 2003). In terms of Information System (IS) dimensions that are independently considered, two IS dimensions, namely system usage and user satisfaction, have been extensively used as dependent variables in prior research (Jeyaraj, 2020). System usage has been used as the dependent variable in many studies with different models. Studies in the technology acceptance domain employing various models such as the Technology Acceptance Model (TAM) and Unified Theory of Acceptance and Use of Technology (UTAUT) their variants have also extensively examined system usage. However, the TAM model, for example, has only two important factors of perceived usefulness and perceived ease of use contributing to the intention to use or the system's use (Davis, 1989) and this model is simple, but it is rather limited in the sense that researchers may need to add other factors or constructs.

The DeLone and McLean IS model is more comprehensive and versatile compared to other acceptance models. To examine the success of a technological system such as the LMS, DeLone and McLean (2003) have proposed a process model where six factors of information quality, system quality, service quality, user satisfaction, individual impact and organizational impact constitute the major characteristics. Information quality, system quality and service quality refer to the characteristics of the system itself as well as of the provider. This model is also versatile because other different factors, which may be represented, for example, as organizational impact and individual impact, can be used together to make the model more sufficient in describing different types of technologies. As a process model, the D\&M model has also been extended to include the detailing of the major characteristics or to include other characteristics relevant to the nature of the system of technology being studied. The D\&M model is generally recognized and commonly utilized in studies, including e-commerce, cloud computing and internet banking (Angelina, Hermawan and Suroso, 2019; Lian, 2017; Jagannathan, Balasubramanian and Natarajan, 2018). In Malaysia, the D\&M model has been used in the study of accounting information systems (Urus et al., 2020).

The D\&M model has been used to study e-learning, mobile-learning and LMS in several countries. For instance, a study on mobile LMS has been done in Korea (Lee and Jeon, 2020) while a study on mobile-learning apps has been carried out in Taiwan (Wang et al., 2019). Motivated by the challenge faced by Romanian universities in the implementation of LMS towards the aim of having blended learning environment, a study on the LMS has been done in Romania (Dorobat, Corbea and Muntean, 2019). Findings in a study on LMS in Singapore showed that system quality and service quality had a significant relationship with LMS usage (Chaw and Tang, 2018). Results from a study on students in Sri Lanka have indicated that information quality, system quality, services quality have significant impact on student satisfaction of the LMS (Nawaz, 2019). In a study on e-learning in 
Malaysia, the study has used the characteristics of information quality, system quality and service quality (Taat and Francis, 2020).

For the LMS, to a great extent, its success in terms of usage depends on user satisfaction. Convenience has been found to influence students' satisfaction with e-learning (Cole, Shelley and Swartz, 2014). A study on determinants of digital content adoption has confirmed that convenience has a significant indirect effect on user satisfaction with digital content (Hidayat-ur-Rehman et al., 2020). User satisfaction subsequently leads to the continuance of use. These results imply that if users find digital content convenient to use, then they are more likely to continue using the technology. By referring to convenience as the necessary time or effort required for using a technology, a study has incorporated convenience among the factors affecting user satisfaction with commercial e-book stores (Huang, Shiau and Lin, 2017).

\section{Proposed Research Model}

In this research, the updated D\&M model has been modified by including convenience as a novel factor relevant to the LMS usage being studied where LMS usage and convenience are considered as the organizational impact and the individual impact, respectively. The modified proposed model consists of six factors: system quality, information quality, service quality, convenience, student satisfaction and LMS usage. The proposed research model is displayed in Figure 1, followed by the description of each factor and the formulation of hypotheses.

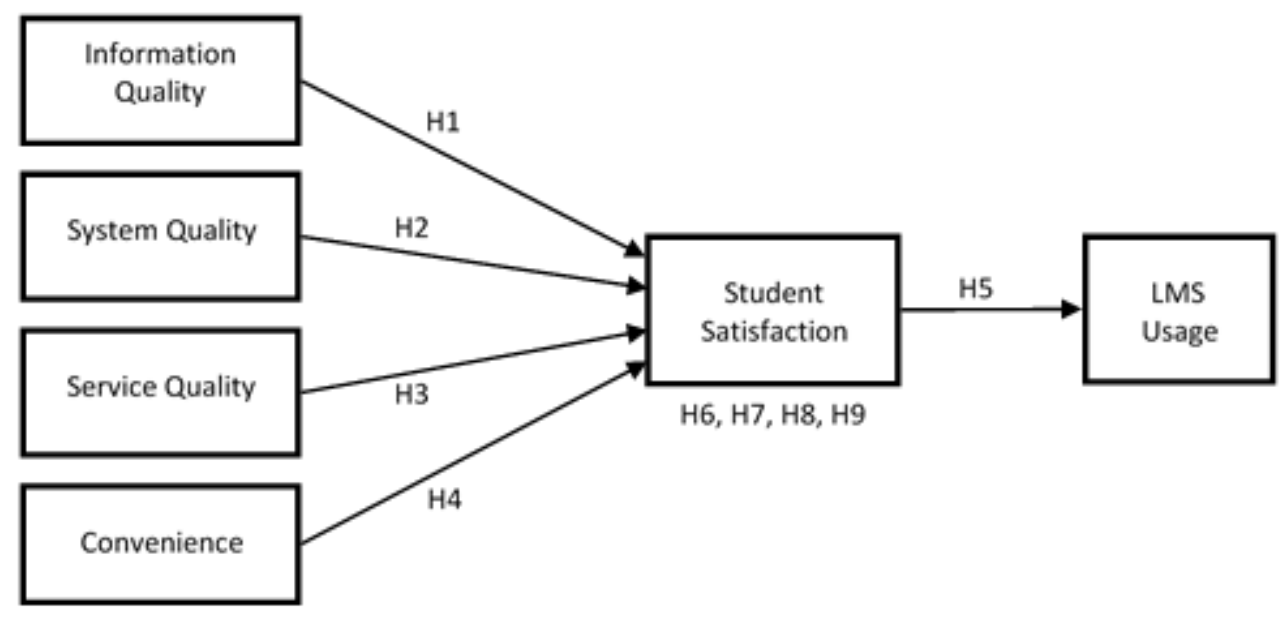

Figure 1: Proposed Research Model

\subsection{LMS Usage (LM)}

LMS usage may refer to actual usage by measuring the students' actions in using the LMS (Yakubu and Dasuki, 2018). LMS actual usage can be measured by usage frequency, time duration and nature of use (Aldholay et al., 2018). Both frequent and efficient use of the LMS would likely improve students' learning performance (Abdekhoda et al., 2016). A meta-review study on D\&M models of information system success yields several measures of actual usage through extent of use other than frequency, such as deep structure use and breadth of use (Jevaraj, 2020). However, since user resistance is one of the main obstacles to the adoption and implementation of LMS, comprehensive adoption by users would depend heavily on user acceptance (Abdekhoda et al., 2016).

Therefore, in this study, LMS usage is defined as the extent to which a student finds using LMS to be acceptable in the sense that it is a good idea and that it is likable as well as pleasurable. This definition is applicable even in the case where institutions have made it compulsory for students to use LMS.

\subsection{Student Satisfaction (SS) and LMS Usage (LM)}

Student satisfaction refers to the students' evaluation of their overall experience of using the LMS (Wang et al., 2019). Students judge and decide on their continuance decisions regarding LMS usage based on their level of satisfaction. The feeling of satisfaction with the e-learning systems determines students' desire to use them (Ghazal et al., 2018). If the LMS is perceived as satisfactory by students, then the student satisfaction level would 
be evaluated as satisfactory (Mtebe and Raphael, 2018). In this study, student satisfaction refers to the student's evaluation of the LMS application with respect to the LMS's quality and their own expectations.

\subsection{Information Quality (IQ) and Student Satisfaction (SS)}

Information quality is defined as the output characteristics offered by the system including relevancy, accuracy and consistency (DeLone and McLean, 2003). As stated by prior works of research, user satisfaction in regard to e-learning technology including LMS is positively influenced by information quality (Ghazal et al., 2018; Chaw and Tang, 2018; Abdallah, Ahlan and Abdullah, 2019; Ohliati and Abbas, 2019).

In this study, the definition of information quality refers to the students' evaluation of the quality of uploaded educational resources in the LMS in terms of accuracy, sufficiency, preciseness and timeliness. The corresponding hypothesis of this factor is formed as follows:

H1: Information quality has a positive impact on student satisfaction.

\subsection{System Quality (SQ) and Student Satisfaction (SS)}

System quality refers to the characteristics of the system including ease of use and ease of understanding (Mtebe and Raphael, 2018). Moreover, since system quality is well considered as one of the essential factors impacting user satisfaction of a technology such as the LMS, various studies have called attention to the impact of system quality on user satisfaction with regard to the technology being studied (DeLone and McLean, 2003; Abdallah, Ahlan and Abdullah, 2019).

In this study, system quality is defined as the student's perception of the efficiency of the LMS in terms of user friendliness, ease of access as well as time and location flexibility of access. It is hypothesized that students' satisfaction with the LMS can be determined partly by the quality of the features of such a system. The corresponding hypothesis of this factor is formed as follows:

H2: System quality has a positive impact on student satisfaction.

\subsection{Service Quality (SEQ) and Student Satisfaction (SS)}

Service quality is defined as the support or assistance that can be provided by the service provider of the information system (Abdallah, Ahlan and Abdullah, 2019). Furthermore, it refers not only to the provision of such support, but also to the timely availability of different communication channels to help users solve arising problems related to the LMS. The provision of system support services for users is considered as one of the most important responsibilities of an institution, since system support can have the greatest impact on the successful usage of the system (Raphael, 2016; Mtebe and Raphael, 2018).

Therefore, it is important to include service quality as one of the factors that can have an impact on student satisfaction. In this study, service quality is defined as the quantity and quality of support or assistance available and provided by the service provider with respect to the system use of the LMS. The corresponding hypothesis of this factor is formed as follows:

H3: Service quality has a positive impact on student satisfaction.

\subsection{Convenience (C) and Student Satisfaction (SS)}

In an online technology study involving mobile hotel bookings, it was discovered that convenience has a positive effect on user loyalty to technology (Ozturk et al., 2016). For LMS usage, convenience refers to a student's perception of convenience with respect to freedom in terms of time, place and execution that is being felt as a result of using the LMS. The student perceives convenience due to the capability of technology, including in making study information available and in enabling easy and swift contact with the lecturers and with other students (Mokhtar, Katan and Hidayat-ur-Rehman, 2018).

In this study, convenience is defined as a student's perception of convenience in terms of the freedom of study time, the ease of effort to study, the accessibility of study materials and activities as well as the perceived potential study benefit with respect to the use of the LMS. The following corresponding hypothesis is formed: H4: Convenience has a positive impact on student satisfaction.

\subsection{Further Formulation of Hypotheses}

The formulation of hypothesis for the relationship between student satisfaction and LMS usage is as follows: 
H5: Student satisfaction has a positive impact on LMS usage.

Student satisfaction is considered as a mediation factor between LMS usage and each of the four factors of information quality, system quality, service quality and convenience. Hence, the following hypotheses are formulated:

H6: Student satisfaction mediates the relationship between information quality and LMS usage.

H7: Student satisfaction mediates the relationship between system quality and LMS usage.

H8: Student satisfaction mediates the relationship between service quality and LMS usage.

H9: Student satisfaction mediates the relationship between convenience and LMS usage.

\section{Methodology}

In this study, the target population are undergraduate and postgraduate students in Malaysian public universities. The sample consists of students from two universities in Malaysia: Universiti Sains Malaysia and Universiti Utara Malaysia. The universities have been utilizing Moodle as the LMS platform. The research has used a quantitative approach using online survey conducted through GOOGLE form. The links to the form have been shared with the students through the WhatsApp group of lecturers as well as through emails of students. Using a convenient sampling technique, this study has employed a cross-sectional survey method. 212 students participated in the data collection. With respect to the selection of sample size, a minimum sample size in a range of 150-400 has been suggested for the analysis using a structural equation model (Hair et al., 2006).

This research utilizes questionnaire items where the research questionnaire is divided into two sections. The first section contains questions regarding the participants' demographic profiles, consisting of students' age, gender, level of education, and years of using the LMS, as well as the type of primary device they use to access the LMS. The descriptive information obtained by SPSS version 22 pertaining to the profile of the respondents is presented in Table 1.

Table 1: Profile of the respondents

\begin{tabular}{llll}
\hline Variable & Description & Number of Respondents & \% \\
\hline Gender & Female & 140 & 66 \\
Age & Male & 72 & 34 \\
& $18-20$ & 124 & 58.5 \\
Student Level & $21-24$ & 25 & 11.8 \\
& Above 24 & 63 & 29.7 \\
Years of using LMS & Undergraduate & 194.5 \\
& Postgraduate & 18 & 8.5 \\
& & & 58.5 \\
Primary device used to access the LMS & Less than 1 year & 124 & 20.8 \\
& $1-3$ years & 44 & 20.8 \\
& Over 3 years & 44 & 59 \\
& Laptop & 125 & 0.9 \\
& Tablet & 2 & 35.8 \\
\hline
\end{tabular}

The second section of the questionnaire focuses on responses with regard to the key constructs of the research framework, namely information quality, system quality, service quality, convenience, student satisfaction and LMS usage.

This section consists of 22 items capturing responses on a seven-point Likert scale ranging from (1) "Strongly disagree" to (7) "Strongly agree". The items for the constructs have been adopted from previous studies related to this research. In this regard, the items for information quality (IQ), system quality(SQ) and service quality (SEQ) have been adopted from Abdallah, Ahlan and Abdullah (2019). Meanwhile, convenience (C), student satisfaction (SS) and LMS usage (LM) have been adopted from Mokhtar, Katan and Hidayat-ur-Rehman (2018), Wang et al. (2019) and Abdekhoda, et al. (2016) respectively. The questionnaire items for each construct are given in Table 2.

Table 2: Measurement Constructs 


\begin{tabular}{|c|c|c|}
\hline Construct & Code & Questionnaire item \\
\hline \multirow[t]{4}{*}{ Information Quality } & IQ1 & LMS can provide me accurate information. \\
\hline & IQ2 & LMS can provide me with sufficient information to do my tasks. \\
\hline & IQ3 & LMS can provide the precise information I need. \\
\hline & IQ4 & LMS can provide updated information regarding my tasks. \\
\hline \multirow[t]{4}{*}{ System Quality } & SQ1 & LMS has a well-designed user interface. \\
\hline & SQ2 & LMS offers flexibility as to time and place of use. \\
\hline & SQ3 & LMS language and means of communication are effective. \\
\hline & SQ4 & I can easily access LMS anytime I need to use it. \\
\hline \multirow[t]{4}{*}{ Service Quality } & SEQ1 & Training on the operation of LMS is sufficient. \\
\hline & SEQ2 & I can communicate with the technicians through multiple channels. \\
\hline & SEQ3 & The training provided can enhance my ability to use LMS. \\
\hline & SEQ4 & In general, the university provides enough support to help using LMS. \\
\hline \multirow[t]{4}{*}{ Convenience } & $\mathrm{C} 1$ & $\begin{array}{l}\text { Using LMS enables me to search for the information/content for my } \\
\text { study, without time constraints. }\end{array}$ \\
\hline & $\mathrm{C} 2$ & $\begin{array}{l}\text { Using LMS saves my effort in performing my study and assignments } \\
\text { activities. }\end{array}$ \\
\hline & $\mathrm{C} 3$ & Using LMS allows me to improve learning outcomes. \\
\hline & $\mathrm{C} 4$ & I can conveniently access and use LMS quickly \\
\hline \multirow[t]{3}{*}{ Student Satisfaction } & SS1 & I am satisfied with the LMS applications. \\
\hline & SS2 & The LMS application is of high quality. \\
\hline & SS3 & The LMS application has met my expectations \\
\hline \multirow[t]{3}{*}{ LMS Usage } & LM1 & Using LMS is good idea. \\
\hline & LM2 & Working with LMS is a pleasure. \\
\hline & LM3 & I like working with LMS. \\
\hline
\end{tabular}

\subsection{Construct Reliability}

A pilot study, consisting of 20 participants, has been carried out using a Google form to assess the reliability of the constructs. The scale reliability test has been performed to obtain the Cronbach's alpha reliability coefficient. For each of the constructs used in this research, the Cronbach alpha values observed are over 0.8 as shown in Table 3. The Cronbach's alpha values within the range of 0.8 and 0.9 are considered very good while Cronbach's alpha values more than 0.9 are considered excellent (Nawi et al., 2020). Thus, the internal reliability of the constructs used in this study has been established.

Table 3: Reliability of Constructs

\begin{tabular}{lcc}
\hline Latent Construct & No. of items & Cronbach's Alpha \\
\hline IQ & 4 & 0.911 \\
SQ & 4 & 0.858 \\
SEQ & 4 & 0.910 \\
C & 4 & 0.902 \\
SS & 3 & 0.912 \\
LM & 3 & 0.912 \\
\hline
\end{tabular}

\section{Results and Analysis}

Data analysis of Partial Least Squares Structural Equation Modeling (PLS-SEM) has been done with SmartPLS 3.2.8. The comprehensive two-step statistical approach of PLS-SEM consists of the establishment of a measurement model and a structural model. 


\subsection{Measurement Model}

The two-step statistical approach towards modelling a PLS-SEM model begins with the establishment of the measurement model. To accomplish this establishment, the data of 212 participants have been analyzed using PLS-SEM where corresponding required values, including composite reliability (CR) and average variance extracted (AVE) are obtained. The measurement model with respect to PLS-SEM, examines the constructs' reliability and validity with respect to the calculated main loading values acceptable for each item of the construct used in this study.

Table 4 tabulates the acceptable main loading values for each item of the construct used this study as well as values of CR and AVE. The questionnaire item C3 has been found to be unsuitable for the measurement model due to the low main loading value and has been deleted. Thus, it can be observed from Table 4 that each of the remaining items has main loading value of more than 0.708 . The value of 0.708 has been suggested as a rule of thumb for the lower value of acceptable main loading value (Hair et al., 2019).

In examining the reliability of the constructs with respect to the remaining items, it has been found that the $C R$ value for each of the constructs has been found to be above 0.70 , gratifying the rule of thumb presented by Hair et al. (2019). For example, the construct C has a CR value of 0.939 as can be observed in Table 4.

The AVE values given in Table 4 indicates the validity of the constructs used in this study. A construct with AVE value of above 0.5 is considered satisfactory in terms of convergence validity (Hair et al., 2019). Therefore, all values of AVE in this study are of satisfactory degree of convergence validity.

Table 4: Measurement Model

\begin{tabular}{|c|c|c|c|c|}
\hline Latent Construct & Items & Main Loading & CR & AVE \\
\hline \multirow[t]{3}{*}{ C } & $\mathrm{C} 1$ & 0.902 & 0.939 & 0.836 \\
\hline & $\mathrm{C} 2$ & 0.928 & & \\
\hline & $\mathrm{C} 4$ & 0.913 & & \\
\hline \multirow[t]{4}{*}{ IQ } & IQ1 & 0.893 & 0.937 & 0.789 \\
\hline & IQ2 & 0.907 & & \\
\hline & IQ3 & 0.870 & & \\
\hline & IQ4 & 0.883 & & \\
\hline \multirow[t]{4}{*}{ SEQ } & SEQ1 & 0.895 & 0.937 & 0.787 \\
\hline & SEQ2 & 0.846 & & \\
\hline & SEQ3 & 0.907 & & \\
\hline & SEQ4 & 0.899 & & \\
\hline \multirow[t]{4}{*}{ SQ } & SQ1 & 0.777 & 0.904 & 0.703 \\
\hline & SQ2 & 0.860 & & \\
\hline & SQ3 & 0.851 & & \\
\hline & SQ4 & 0.863 & & \\
\hline \multirow[t]{3}{*}{ SS } & SS1 & 0.928 & 0.945 & 0.851 \\
\hline & SS2 & 0.910 & & \\
\hline & SS3 & 0.928 & & \\
\hline \multirow[t]{3}{*}{ LM } & LM1 & 0.912 & 0.945 & 0.851 \\
\hline & LM2 & 0.954 & & \\
\hline & LM3 & 0.928 & & \\
\hline
\end{tabular}

\subsection{Validation of the measurement model}

Discriminant validity of Heterotrait-Monotrait (HTMT) ratio is used to validate the measurement model. The value of 0.90 has been used in prior studies for the construct maximum threshold of HTMT ratio (Gold, Malhotra and Segars, 2001; Hair et al., 2019). With respect to this threshold value, results given in Table 5 indicate the validation of the measurement model. 
Table 5: Discriminant validity of Heterotrait-Monotrait Ratio (HTMT)

\begin{tabular}{|c|c|c|c|c|c|c|}
\hline Construct & $\mathrm{C}$ & IQ & LM & SEQ & SQ & SS \\
\hline \multicolumn{7}{|c|}{$\mathrm{C}$} \\
\hline IQ & 0.831 & & & & & \\
\hline LM & 0.900 & 0.796 & & & & \\
\hline SEQ & 0.811 & 0.786 & 0.752 & & & \\
\hline SQ & 0.869 & 0.886 & 0.863 & 0.866 & & \\
\hline SS & 0.886 & 0.846 & 0.878 & 0.842 & 0.887 & \\
\hline
\end{tabular}

\subsection{Structural Model}

Having established the measurement model, the second step of the two-step statistical approach toward modelling a PLS-SEM model is to establish the structural model. Path coefficients as well as described variances are included in the structural model. Bootstrapping procedure has been used to sharpen the regression coefficients (or the beta values) by obtaining bootstrap standard errors where 5000 random subsamples have been extracted from one original sample with replacements. A constant repetition of such a process is required of which 5000 is the typical number (Hair et al., 2019). Subsequently, the PLS path model has been estimated using these subsamples.

The results pertaining to the significance of the paths corresponding to hypotheses $\mathrm{H} 1, \mathrm{H} 2, \mathrm{H} 3, \mathrm{H} 4$ and $\mathrm{H} 5$ are tabulated in Table 6. It can be observed the $p$-values obtained for the paths indicate that hypotheses $\mathrm{H} 1, \mathrm{H} 2, \mathrm{H} 3$, $\mathrm{H} 4$ and $\mathrm{H} 5$ are supported.

Table 6: Significance of direct effects - Path coefficients $(n=212)$

\begin{tabular}{lllllll}
\hline Hypothesis & Path & Beta value & SE & t-value & p-values & Result \\
\hline H1 & IQ $->$ SS & 0.202 & 0.082 & $2.447^{*}$ & 0.007 & Supported \\
H2 & SQ $->$ SS & 0.194 & 0.079 & $2.449^{*}$ & 0.007 & Supported \\
H3 & SEQ $->$ SS & 0.224 & 0.058 & $3.840^{* *}$ & 0.000 & Supported \\
H4 & $\mathrm{C}->$ SS & 0.342 & 0.086 & $3.991^{* *}$ & 0.000 & Supported \\
H5 & SS $->$ LM & 0.807 & 0.031 & $25.696^{* *}$ & 0.000 & Supported \\
\hline Note: ${ }^{*} \mathrm{p}<0.05, \mathrm{t}>1.645, * * p<0.01, t>2.327, * * * p<0.001, t>3.092$ (one tailed); SE: Standard
\end{tabular}

An evaluation regarding the significance of the PLS structural model's indirect path, which is the mediating effect, has also been performed following the bootstrapping of 5000 random subsamples. Mediation is assumed to take place when there exists a statistical significance in the indirect relationship between the independent and the dependent variables (Hayes and Preacher, 2014). Using path analysis, the estimates are calculated and the results are given in Table 7. The corresponding four indirect relationships have been proven to have statistical significance where the p-values obtained for the indirect paths indicate that hypotheses $\mathrm{H} 6, \mathrm{H} 7, \mathrm{H} 8$ and $\mathrm{H} 9$ are supported.

Table 7: Significance of specific indirect effects - Path coefficients $(n=212)$

\begin{tabular}{lllllll}
\hline Hypothesis & Path & Beta value & SE & p-values & t-value & Result \\
\hline H6 & IQ -> SS -> LM & 0.163 & 0.067 & 0.015 & 2.437 & Supported \\
H7 & SQ -> SS -> LM & 0.156 & 0.064 & 0.014 & 2.446 & Supported \\
H8 & SEQ -> SS -> LM & 0.181 & 0.048 & 0.000 & 3.775 & Supported \\
H9 & C $>$ SS -> LM & 0.276 & 0.073 & 0.000 & 3.775 & Supported \\
\hline
\end{tabular}

Note: ${ }^{*} \mathrm{p}<0.05, \mathrm{t}>1.96,{ }^{* *} \mathrm{p}<0.01, \mathrm{t}>2.58$ (two tailed); SE: Standard Error

With regard to effect size, a few guidelines stated by Cohen (1988) have been followed in this study in terms of value assessment in the independent constructs or variables towards the prediction of the dependent constructs or variables. By evaluating the effect size related to the connecting path between each independent construct and its corresponding dependent construct, the model's fit can be decided. Moreover, each independent construct's impact power on its related dependent construct signifies the effect size (Cohen, 1988). Using 0.02, 0.15 and 0.35 to respectively be small, medium and large values for the effect size, the obtained values of 0.071 for the SEQ on SS, 0.053 for IQ on SS and 0.043 for SQ on SS are all considered to be of small effect sizes, whereas the value of 0.156 for the effect size of construct $C$ on SS falls under the category of a medium effect size. 


\subsection{Validation of the structural model}

In this study, both R-square value $\left(R^{2}\right)$ and Stone-Geisser's $Q^{2}$ have been used to validate the structural model. Aside from taking the magnitude of the value of $R^{2}$ into consideration, the Stone-Geisser's $Q^{2}$ is a technique which can be employed as a criterion to determine predictive relevance. This technique has been used to evaluate the prediction capabilities of the research model (Henseler, Ringle and Sinkovics, 2009). Values of $Q^{2}$ exceeding zero specify the existence of predictive relevance in the independent constructs in regard to the dependent construct (Hair et al., 2019).

Figure 2 provides an illustrative display of the paths considered in the PLS model where it portrays some similar values that have been given in Table 6. For example, the value of 0.342 on the path of $C$ to SS in Figure 2 refers to the same coefficient value as given in Table 6 . With regard to the validation of the structural model, it can be observed in Figure 2 that the $\mathrm{R}^{2}$ value obtained with respect to the direct effect of the four independent variables of IQ, SQ, SEQ and C on SS is 0.757 , while the value corresponding to the impact of SS on LM is 0.652 . These results indicate a strong fit of the model, as suggested by Cohen (1988), where $R^{2}$ values of .02, .13, and .26 are considered as weak, medium, and strong, respectively. In addition to that, the results from the validation of the model using Stone Geisser's $Q^{2}$ technique indicates outstanding predictive relevance for the research model where the obtained value for the variables of IQ, SQ, SEQ and C on SS is 0.601 while the value corresponding to the impact of SS on LM is 0.531 .

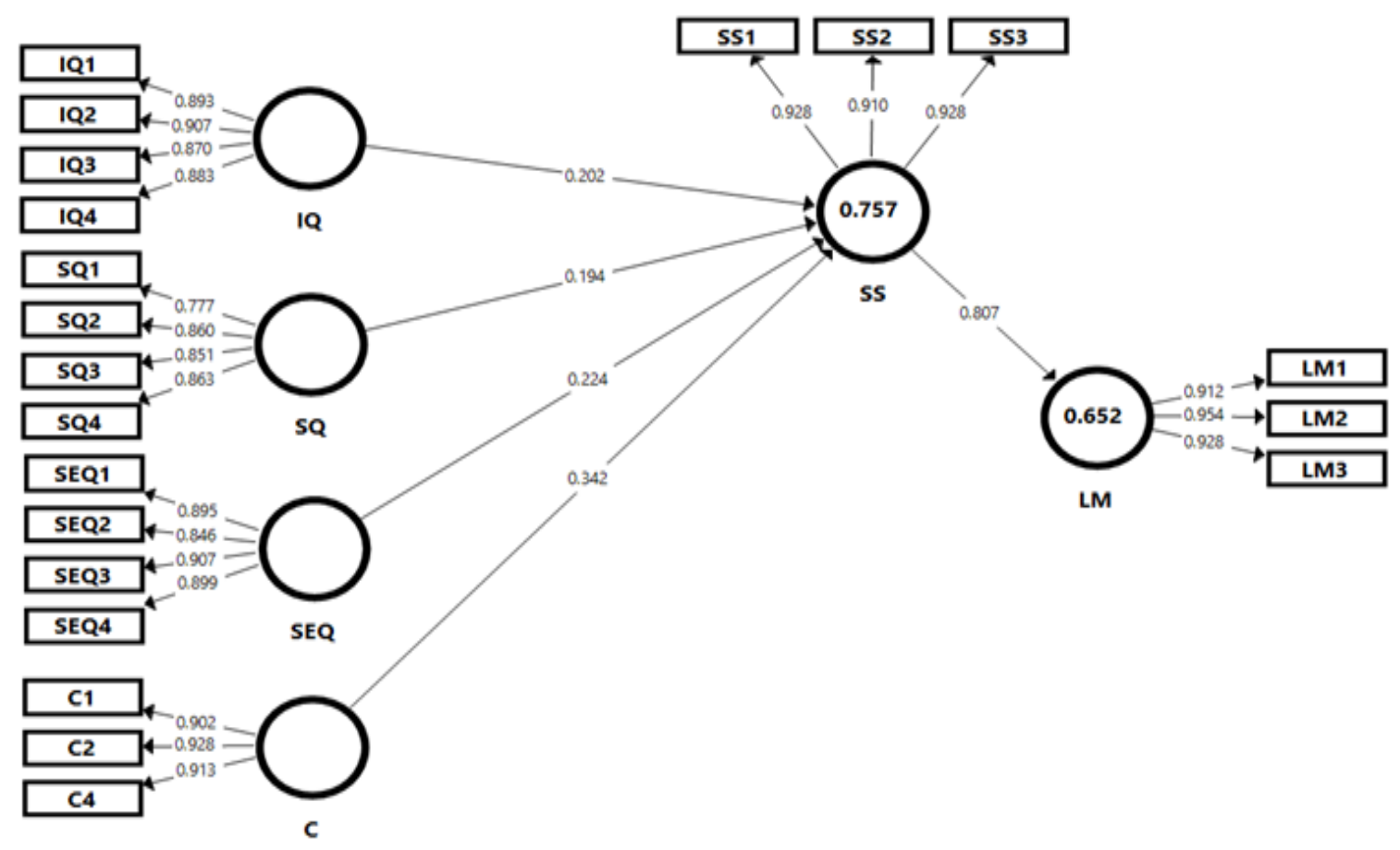

Figure 2: PLS path analysis with $R^{2}$ values

\section{Discussion}

In assessing the quality of the established measurement model with respect to PLS-SEM, the results of the reliability and validity tests of the model indicates that the formulated constructs are reliable and valid. Meanwhile, the validation of the structural model indicates that the obtained model not only has a strong fit but also outstanding predictive relevance.

Based on the results from the established structural model with respect to direct effects, hypotheses $\mathrm{H} 1, \mathrm{H} 2$ and H3 are supported. This implies that information quality, system quality and service quality have positive impact on student satisfaction, similar to the results of Lee and Jeon (2020). In a study by Ohliati and Abbas (2019) information quality and service quality been found to be a significant factor. However, studies by Ghazal et al. 
(2018) and Abdallah, Ahlan and Abdullah, (2019) have yield significant results for information quality and system quality.

In this regard, results confirm that the quality of information provided in the LMS significantly affects student satisfaction. When students are able to ascertain reliability, readability, accuracy and effectively-structured course content as well as an updated LMS, they are more likely to be satisfied when using the corresponding system (Abdallah, Ahlan and Abdullah, 2019; Ghazal et al., 2018).

Results from the established structural model with respect to direct effects also indicate that hypothesis $\mathrm{H} 4$ is supported. This further implies that other than information quality, system quality and service quality, convenience also has positive impact on student satisfaction. In addition, with respect to effect size of the independent variables on student satisfaction, convenience has a larger effect size than information quality, system quality and service quality.

Results with respect to direct effects also indicate that hypothesis $\mathrm{H} 5$ is supported, indicating that student satisfaction has a positive impact on LMS. This implies that when students are satisfied with the system, the LMS is more highly used. Although this is a study of students in Malaysia, the implication may be important other developing countries towards understanding the importance of student satisfaction towards LMS usage in their universities.

For indirect effect or the mediating effect of student satisfaction on LMS usage, the hypothesis $\mathrm{H6}, \mathrm{H} 7, \mathrm{H} 8$ and H9 are all supported. Therefore, student satisfaction has been found to significantly mediates the relationship between each of the four factors and LMS usage where the four independent factors in this study are information quality, system quality, service quality and convenience.

Based on the established structural model, all direct paths as well all indirect paths have been found to be significant. This also implies that all the hypotheses formulated in this study are supported. Therefore, information quality, system quality, service quality and convenience have positive effects on student satisfaction which, in turn, has a significant impact on LMS usage.

\section{Conclusion}

In this paper, a process model of the information system derived from the study of DeLone and McLean has been constructed for LMS. This study is aimed to present a model to evaluate LMS usage for students in higher education in Malaysian universities by adapting the D\&M model, with LMS use as an organizational impact and convenience as an individual impact. In this research, a process model as well as its corresponding metrics have been presented and verified. Towards determining the structure of the model, all paths have been found to be significant. In other words, information quality, system quality, service quality and convenience have positive impacts on student satisfaction, which, in turn, has a significant impact on LMS usage.

In this research, the newly introduced factor convenience, which is considered as individual impact, has been discovered to be a significant factor in determining LMS user satisfaction among university students in Malaysia. Student satisfaction has been found to have the highest effect on LMS usage. This implies that when students are satisfied with the system, the system use increases. The results of the study may help the university's administration in the country understand the importance of student satisfaction of the LMS in their universities. Therefore, having made enormous effort in terms of the funding of infrastructure and manpower with the belief of the importance of the LMS towards enhancing education, the institutions are recommended to change the focus towards enhancing student satisfaction to achieve intended LMS use by the students. Furthermore, in line with the results of this study, to enhance student satisfaction, the institution is also recommended to focus improvements not only on information quality, system quality and service quality but also on convenience as the individual impact on students. Enhancing information quality, system quality and service quality would require training of the relevant providers such as lecturers, instructors, system personnel or coaches, and regular updates of LMS platform. As for enhancing the factor convenience which is considered as individual impact, it is crucial for the institutions to highlight the convenience of using LMS by regularly advertising and promoting the various dimensions of convenience of LMS to the students. 


\section{Suggestions for future research}

The participants of this study on LMS are undergraduate and graduate students in universities in Malaysia. Therefore, it is our suggestion for future researchers to utilize cross-sectional surveys consisting of a larger population of students from a variety of developing countries. In addition, since different information would be uploaded by the providers in the LMS for different areas of study, it is also suggested to look into students of a specific study area where they can make responses while focusing on certain specific courses or area of study, for example, language, mathematics and agriculture.

\section{Acknowledgement}

The authors would like to acknowledge financial support received from Research University Grant, Universiti Sains Malaysia (1001/PJJAUH/8016029).

\section{References}

Abdallah, N., Ahlan, A. R. and Abdullah, O. A., 2019. The role of quality factors on learning management systems adoption from instructor's perspectives. The Online Journal of Distance Education and e-Learning, 7(2), pp. 133-150.

Abdekhoda, M., Dehnad, A., Misaeed, S. J. G. and Gavgani, V. Z., 2016. Factors influencing the adoption of E-learning in Tabriz University. Medical Journal of the Islamic Republic of Iran, 30, pp. 1-7.

Aldholay, A., Isaac, O., Abdullah, Z., Abdulsalam, R. and Al-Shibami, A. H., 2018. An extension of Delone and McLean IS success model with self-efficacy: online learning usage in Yemen. The International Journal of Information and Learning Technology, 35(4), pp. 285-304. https://doi.org/10.1108/IJILT-11-2017-0116

Aldiab, A., Chowdhury, H., Kootsookos, A., Alam, F. and Allhibi, H., 2019. Utilization of Learning Management Systems (LMSs) in higher education system: A case review for Saudi Arabia. Energy Procedia, 160, pp. 731-737. https://doi.org/10.1016/j.egypro.2019.02.186

Angelina, J. R., Hermawan, A. and Suroso, I. A., 2019. Analyzing e-commerce success using DeLone and McLean model. Journal of Information Systems Engineering and Business Intelligence, 5(2), pp. 156-162. http://dx.doi.org/10.20473/jisebi.5.2.156-162

Chaw, L. Y. and Tang, C. M., 2018. What makes learning management systems effective for learning?. Journal of Educational Technology Systems, 47(2), pp. 152-169. https://doi.org/10.1177/0047239518795828

Cohen, J., 1988. Statistical power analysis for the behavioral sciences (2nd ed.). New Jersey: Lawrence Erlbaum Associates.

Cole, M. T., Shelley, D. J. and Swartz, L. B., 2014. Online instruction, e-learning, and student satisfaction: A three year study. International Review of Research in Open and Distance Learning, 15(6), pp. 111-131. https://doi.org/10.19173/irrodl.v15i6.1748

Davis, F. D., 1989. Perceived usefulness, perceived ease of use, and user acceptance of information technology. MIS Quarterly, 13(3), pp. 319-339. https://doi.org/10.2307/249008

Delone, W. H. and McLean, E. R., 2003. The DeLone and McLean model of information system success: A ten year update. Journal of Management Information Systems, 19(4), pp. 9-30. https://doi.org/10.1080/07421222.2003.11045748

Dorobat, I., Corbea, A. M. I. and Muntean, M., 2019. Integrating student trust in a conceptual model for assessing Learning Management System success in higher education: an empirical analysis. IEEE Access, 7, pp. 69202-69214.

Dulkaman, N. and Ali, A. M., 2016. Factors influencing the success of learning management system (LMS) on students' academic performance. International Young Scholars Journal of Languages, 1(1), pp. 36-49.

Gee, N. C., 2018. The impact of lecturers' competencies on students' satisfaction. Journal of Arts and Social Sciences, 1(2), pp. 74-86.

Ghazal, S., Aldowah, H., Umar, I. and Brevell, B., 2018. Acceptance and satisfaction of learning management system enabled blended learning based on a modified DeLone-McLean information system success model. International Journal of Information Technology Project Management, 9(3), pp. 52-71. https://doi.org/10.4018/IJITPM.2018070104

Gold, A. H., Malhotra, A. and Segars, A. H., 2001. Knowledge management: an organizational capabilities perspective. Journal of Management Information Systems, 18 (1), pp. 185-214. https://doi.org/10.1080/07421222.2001.11045669

Hair, J. F., Black, W. C., Babin, B. J., Anderson, R. E. and Tatham, R. L., 2006. Multivariate data analysis (6th ed.). Upper Saddle River, NJ: Pearson University Press.

Hair, J.F., Risher, J. J., Sarstedt, M. and Ringle, C. M., 2019. When to use and how to report the results of PLS-SEM. European Business Review. 31(1), pp. 2-24. https://doi.org/10.1108/EBR-11-2018-0203

Hayes, A.F. and Preacher, K.J., 2014. Statistical mediation analysis with a multicategorical independent variable. British Journal of Mathematical and Statistical Psychology, 67, pp. 451-470. https://doi.org/10.1111/bmsp.12028

Henseler, J., Ringle C. M. and Sinkovics R. R., 2009. The use of partial least squares path modeling in international marketing. Advances in International Marketing, 20, pp. 277-319. https://doi.org/10.1108/S1474-

7979(2009)0000020014 
Hidayat-ur-Rehman, I., Akram, M. S., Malik, A., Mokhtar, S. A., Bhatti, Z. A. and Khan, M. A., 2020. Exploring the determinants of digital content adoption by academics: The moderating role of environmental concerns and price value. SAGE Open, 10(2), pp. 1-15. https://doi.org/10.1177/2158244020931856

Huang, L-C., Shiau,W-L. and Lin, Y-H., 2017. What factors satisfy e-book store customers? Developmentof a model to evaluate e-book user behavior and satisfaction. Internet Research, 27 (3), pp. 563-585. https://doi.org/10.1108/IntR05-2016-0142

Jagannathan, V., Balasubramanian, S. and Natarajan, T., 2018. An extension to the Delone and Mclean information systems success model and validation in the internet banking context. In: Encyclopedia of Information Science and Technology, 4th edition, USA: IGI Global, pp. 49-60. https://doi.org/10.4018/978-1-5225-2255-3.ch004

Jeyaraj, A., 2020. DeLone \& McLean models of information system success: Critical meta-review and research directions. International Journal of Information Management, 54, pp. 102-139. https://doi.org/10.1016/ji.jinfomgt.2020.102139

Lee, Y. and Jeon, J. Y., 2020. The difference of user satisfaction and net benefit of a mobile learning management system according to self-directed learning: an investigation of cyber university students in hospitality. Sustainability, 12(7), pp. 1-13. https://doi.org/10.3390/su12072672

Lian, J-W., 2017. Establishing a cloud computing success model for hospitals in Taiwan. NQUIRY: The Journal of Health Care Organization, Provision, and Financing, 54, pp. 1-6. https://doi.org/10.1177/0046958016685836

Ministry of Higher Education Malaysia. 2015. Ministry Education Blueprint (2015-2025). In Putrajaya: Ministry of Higher Education Malaysia.

Mokhtar, S. A., Katan, H. and Hidayat-ur-Rehman I., 2018. Instructors' behavioral intention to use learning management system: An integrated TAM perspective. TEM Journal, 7(3), pp. 513-525. https://doi.org/10.18421/TEM73-07

Mtebe, S. and Raphael, C., 2018. Key factors in learners' satisfaction with the e-learning system at the university of Dar es Salaam, Tanzania. Australasian Journal of Educational Technology, 34(4), pp. 107-122.

Nawaz, S. S., 2019. Effectiveness of LMS: Moodle perspective from south eastern university of Sri Lanka. International Journal of Grid and Distributed Computing, 12(3), pp. 172-189.

Nawi, F. A. M., Tambi, A. M., Samat, M. F. and Mustapha, W. M. W., 2020. A review on the internal consistency of a scale: the empirical example of the influence of human capital investment on malcom baldridge quality principles in tvet institutions. Asian People Journal, 3(1), 19-29. https://doi.org/10.37231/apj.2020.3.1.121

Ohliati, J. and Abbas, B. S., 2019. Measuring students satisfaction in using learning management system. International Journal of Emerging Technologies in Learning (iJET), 14(4), pp. 180-189. https://doi.org/10.3991/ijet.v14.i04.9427

Ozturk, A. B., Bilgihan, A., Nusair, K. and Okumus, F., 2016. What keeps the mobile hotel booking users loyal? Investigating theroles of self-efficacy, compatibility, perceived ease of use, and perceived convenience. International Journal of Information Management, 36 (6), pp. 1350-1359. https://doi.org/10.1016/jijinfomgt.2016.04.005

Rahman, M. H. A., Uddin, M. S. and Dey, A., 2021. Investigating the mediating role of online learning motivation in the COVID-19 pandemic situation in Bangladesh. Journal of Computer Assisted Learning, pp. 1-15. https://doi.org/10.1111/jcal.12535

Raphael, C., 2016. Student support services: A case of blended learning in higher learning institutions in Tanzania. In: J. Keengwe, J. Mbae, and G. Onchwari (Eds.), Handbook of research on global issues in next-generation teacher education. Hershey PA: IGI Global. (pp. 188-205).

Soffer, T. and Nachmias, R., 2018. Effectiveness of learning in online academic courses compared with face-to-face courses in higher education. Journal of Computer Assisted Learning, 34(5), pp. 534-543. https://doi.org/10.1111//ical.12258

Taat, M. S. and Francis, A., 2020. Factors influencing the students' acceptance of e-learning at teacher education institute: an exploratory study in Malaysia. International Journal of Higher Education, 9(1), pp. 133-141. https://doi.org/10.5430/ijhe.v9n1p133

Thongsri, N., Shen, L. and Bao, Y., 2019. Investigating factors affecting learner's perception toward online learning: evidence from ClassStart application in Thailand. Behaviour \& Information Technology, 38(12), pp. 1243-1258. https://doi.org/10.1080/0144929X.2019.1581259

Urus, S.T., Hasim, K., Nazri, S. N. F. S. M. and Mat, T. Z. T., 2020. Critical success factors of accounting information systems (AIS): Empirical evidence from Malaysian organizations. Management \& Accounting Review (MAR), 19(1), pp. 233266.

Venkatesh, V., Morris, M. G., Davis, G. B. and Davis, F. D., 2003. User acceptance of information technology: Toward an unified view. MIS Quarterly, 27(3), pp. 425-478. https://doi.org/10.2307/30036540

Wang, Y., Wang, S., Lin, H. and Tsai, H., 2019. Developing and validating a model for assessing paid mobile learning app success. Interactive Learning Environments, 27(4), pp. 458-477. https://doi.org/10.1080/10494820.2018.1484773

Yakubu, M. N. and Dasuki, S. I., 2018. Assessing eLearning systems success in Nigeria: An application of the DeLone and McLean information systems success model. Journal of Information Technology Education: Research, 17, pp. $183-203$. 